\title{
The Influence of $\Delta$ FosB in the Nucleus Accumbens on Natural Reward-Related Behavior
}

\author{
Deanna L Wallace, ${ }^{1,2}$ Vincent Vialou, ${ }^{1,2}$ Loretta Rios, ${ }^{1,2}$ Tiffany L. Carle-Florence, ${ }^{1,2}$ Sumana Chakravarty, ${ }^{1,2}$ \\ Arvind Kumar, ${ }^{1,2}$ Danielle L. Graham, ${ }^{1,2}$ Thomas A. Green, ${ }^{1,2}$ Anne Kirk, ${ }^{1,2}$ Sergio D. Iñiguez, ${ }^{3}$ Linda I. Perrotti, ${ }^{1,2,4}$ \\ Michel Barrot, ${ }^{1,2,5}$ Ralph J. DiLeone, ${ }^{1,2,6}$ Eric J. Nestler, ${ }^{1,2}$ and Carlos A. Bolaños-Guzmán ${ }^{1,2,3}$ \\ Departments of ${ }^{1}$ Psychiatry and ${ }^{2}$ Neuroscience, The University of Texas Southwestern Medical Center, Dallas, Texas 75390-9070, ${ }^{3}$ Department of \\ Psychology, Florida State University, Tallahassee, Florida 32306, ${ }^{4}$ Department of Psychology, The University of Texas at Arlington, Arlington, Texas 76019, \\ ${ }^{5}$ Institut des Neurosciences Cellulaires et Intégratives Unité Mixte de Recherche 7168, Centre National de la Recherche Scientifique and University Louis \\ Pasteur, 67084 Strasbourg, France, and ${ }^{6}$ Department of Psychiatry, Yale University School of Medicine, New Haven, Connecticut 06508
}

The transcription factor deltaFosB $(\triangle \mathrm{FosB})$, induced in nucleus accumbens (NAc) by chronic exposure to drugs of abuse, has been shown to mediate sensitized responses to these drugs. However, less is known about a role for $\Delta$ FosB in regulating responses to natural rewards. Here, we demonstrate that two powerful natural reward behaviors, sucrose drinking and sexual behavior, increase levels of $\Delta \mathrm{FosB}$ in the NAc. We then use viral-mediated gene transfer to study how such $\Delta$ FosB induction influences behavioral responses to these natural rewards. We demonstrate that overexpression of $\Delta$ FosB in the NAc increases sucrose intake and promotes aspects of sexual behavior. In addition, we show that animals with previous sexual experience, which exhibit increased $\Delta$ FosB levels, also show an increase in sucrose consumption. This work suggests that $\Delta \mathrm{FosB}$ is not only induced in the NAc by drugs of abuse, but also by natural rewarding stimuli. Additionally, our findings show that chronic exposure to stimuli that induce $\Delta \mathrm{FosB}$ in the NAc can increase consumption of other natural rewards.

Key words: behavior; nucleus accumbens; obesity; reward; sex; sucrose; transcription factor

\section{Introduction}

$\Delta$ FosB, a Fos family transcription factor, is a truncated product of the fosB gene (Nakabeppu and Nathans, 1991). It is expressed at relatively low levels compared with other Fos family proteins in response to acute stimuli, but accumulates to high levels in brain after chronic stimulation because of its unique stability (Nestler, 2008). This accumulation occurs in a region-specific manner in response to many types of chronic stimulation, including chronic administration of drugs of abuse, seizures, antidepressant drugs, antipsychotic drugs, neuronal lesions, and several types of stress [for review, see Cenci (2002) and Nestler (2008)].

The functional consequences of $\Delta$ FosB induction are best understood for drugs of abuse, which induce the protein most prominently in the nucleus accumbens (NAc), a response reported for virtually all types of drugs of abuse (Muller and Un-

\footnotetext{
Received April 8, 2008; revised July 25, 2008; accepted Aug. 21, 2008.

This work was supported by grants from the National Institute of Mental Health and National Institute on Drug Abuse and from the National Alliance for Research in Schizophrenia and Depression.

Correspondence should be addressed to Carlos A. Bolanos at the above address. E-mail: bolanos@psy.fsu.edu.

D. L. Wallace's present address: Helen Willis Neuroscience Institute, University of California, Berkeley, Berkeley, CA 94720.

T. L. Carle-Florence's present address: Mary Kay Research Laboratories, Dallas, TX 75379.

D. L. Graham's present address: Merck Laboratories, Boston, MA 02115.

T. A. Green's present address: Virginia Commonwealth University, Richmond, VA 23284.

E. J. Nestler's present address: Department of Neuroscience, Mount Sinai School of Medicine, New York, NY 10029.

DOI:10.1523/JNEUROSCI.1531-08.2008

Copyright $\odot 2008$ Society for Neuroscience $\quad$ 0270-6474/08/2810272-06\$15.00/0
}

terwald, 2005; McDaid et al., 2006; Nestler, 2008; Perrotti et al., 2008). The NAc is part of the ventral striatum and is an important neural substrate for the rewarding actions of abused drugs. Accordingly, increasing evidence suggests that $\Delta \mathrm{FosB}$ induction in this region increases an animal's sensitivity to the rewarding effects of drugs of abuse and may also increase motivation to obtain them. Thus, overexpression of $\Delta$ FosB in the NAc causes animals to develop place preferences to cocaine or to morphine, or to self-administer cocaine, at lower drug doses, and enhances lever pressing for cocaine in a progressive ratio paradigm (Kelz et al., 1999; Colby et al., 2003; Zachariou et al., 2006).

In addition to its role in mediating drug reward, the NAc has been implicated in regulating responses to natural rewards, and recent work has suggested a relationship between natural rewards and $\Delta \mathrm{FosB}$ as well. Voluntary wheel running has been shown to increase $\Delta$ FosB levels in the NAc, and overexpression of $\Delta$ FosB within this brain region causes a steady increase in running, which lasts for several weeks, compared with control animals, whose running plateaus over 2 weeks (Werme et al., 2002). Similarly, a high-fat diet induces $\Delta$ FosB in the NAc (Teegarden and Bale, 2007), whereas $\Delta$ FosB overexpression in this region increases instrumental responding for food reward (Olausson et al., 2006). Additionally, the fos $B$ gene is implicated in maternal behavior (Brown et al., 1996). However, little information is available on the relationship between $\Delta$ FosB and sexual behavior, one of the strongest natural rewards. Moreover, less clear still is the possible involvement of $\Delta$ FosB in more compulsive, even "addic- 
tive," models of natural reward behavior. For example, several reports have demonstrated an addiction-like aspect in sucrose intake paradigms (Avena et al., 2008).

To extend our knowledge of $\Delta$ FosB action in natural reward behaviors, we investigated the induction of $\Delta$ FosB in the NAc in sucrose drinking and sexual behavior models. We also determined how overexpression of $\Delta$ FosB in the NAc modifies behavioral responses to these natural rewards, and whether previous exposure to one natural reward can enhance other natural rewarding behaviors.

\section{Materials and Methods}

All animal procedures were approved by the Institutional Animal Care and Use Committee of University of Texas Southwestern Medical Center.

Sexual behavior. Sexually experienced male Sprague Dawley rats (Charles River) were generated by allowing them to mate with receptive females until ejaculation, $\sim 1-2$ times per week for 8-10 weeks for a total of 14 sessions. Sexual behavior was assessed as described previously (Barrot et al., 2005). Control males were generated by exposure to the same arena and bedding, for the same amount of time, as experienced males. Females were never introduced to the arena with these control males. In a separate experiment, an additional experimental group was generated: males were introduced to a hormone-treated female that had not yet entered estrus. These males attempted mounts and intromissions; however, because females were nonreceptive, sexual behavior was not achieved in this group. Eighteen hours after the last session, animals were perfused or decapitated, and brains were taken for tissue processing. For another group of animals, $\sim 5 \mathrm{~d}$ after the 14th session, sucrose preference was tested as described below. For further details, see supplemental Methods (available at www.jneurosci.org as supplemental material).

Sucrose consumption. In the first experiment (Fig. 1a), rats were given unlimited access to two bottles of water for $2 \mathrm{~d}$, followed by one bottle each of water and sucrose for $2 \mathrm{~d}$ at increasing sucrose concentrations $(0.125-50 \%)$. A $6 \mathrm{~d}$ period of two bottles of water only followed, then $2 \mathrm{~d}$ of one bottle of water and a bottle of $0.125 \%$ sucrose. In the second experiment (Figs. 1b,c, 2), rats were given unlimited access to one bottle each of water and $10 \%$ sucrose for $10 \mathrm{~d}$. Control animals received two bottles of water only. Animals were perfused or rapidly decapitated, and brains were collected for tissue processing.

Two-bottle choice test. A two-bottle choice paradigm was conducted as previously described (Barrot et al., 2002). Before surgery, to control for possible individual differences, animals were pretested during the first 30 min of the dark phase for a two-bottle choice procedure between water and $1 \%$ sucrose. Three weeks after viral-mediated gene transfer (see below) and before any additional behavioral testing, the animals given only water were then tested for a $30 \mathrm{~min}$ two-bottle choice procedure between water and the $1 \%$ sucrose solution.

Sexually experienced and control animals did not have a pretest procedure before sexual behavior. Five days after the 14th session of sexual (or control) behavior, animals were given a two-bottle choice test between water and a $1 \%$ sucrose solution during the first 30 min of their dark-light cycle. Separate groups of sexually experienced and control animals were used for measuring $\Delta$ FosB levels after sexual behavior and for studying the effect of sexual behavior on sucrose preference.

Western blotting. NAc dissections obtained by punch dissection were analyzed by Western blotting as described previously (Perrotti et al., 2004), using a rabbit polyclonal anti-FosB antibody [for antibody characterization, see Perrotti et al. (2004)] and a monoclonal antibody to glyceraldehyde-3-phosphate dehydrogenase (GAPDH) (RDI-TRK5G46C5; Research Diagnostics), which served as a control protein. $\triangle$ FosB protein levels were normalized to GAPDH, and experimental and control samples were compared. For further details, see supplemental Methods (available at www.jneurosci.org as supplemental material).

Immunohistochemistry. Animals were perfused, and brain tissues were treated using published immunohistochemistry methods (Perrotti et al., 2005). Because the last exposure to rewarding stimuli occurred $18-24 \mathrm{~h}$ before analysis, we considered all FosB-like immunoreactivity, detected with a pan-FosB antibody (SC-48; Santa Cruz Biotechnology), to reflect
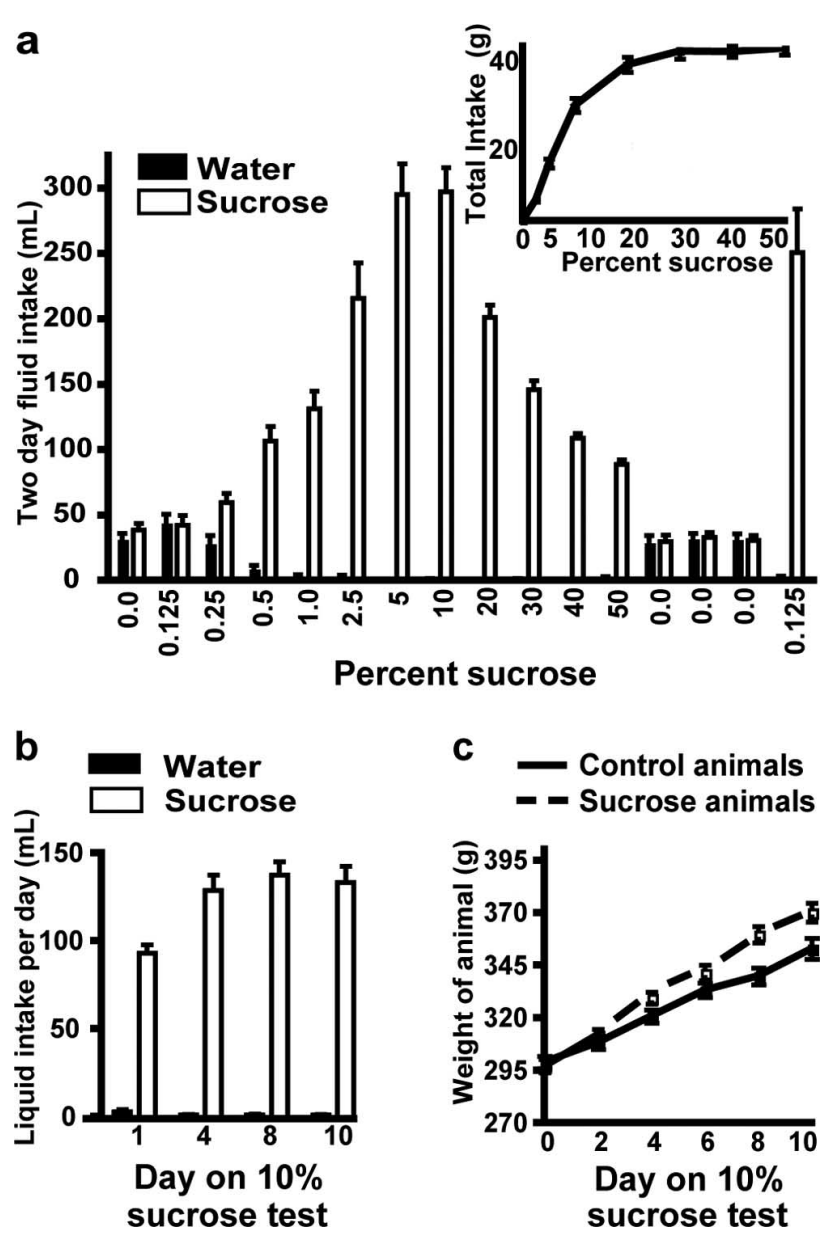

Figure 1. Two-bottle sucrose choice paradigms show escalating sucrose consumption. $\boldsymbol{a}$, Increasing concentrations of sucrose lead to "inverted U-shape" intake behavior, along with relapse-like and sensitization-like behavior after a period of withdrawal [significant difference between water and sucrose intake per $2 \mathrm{~d}$ at each concentration of $0.25 \%$ and subsequent sucrose exposure $\left(t_{(30)}=4.81 ; p<0.001 ; n=8\right.$, corrected for multiple comparisons)]. Inset, Intake represented as total grams of sucrose ingested at each concentration over $2 \mathrm{~d}$, indicating stabilized intake at higher concentrations. $\boldsymbol{b}$, Animals on $10 \mathrm{~d}$ of two-bottle choice paradigm show increasing amounts of sucrose intake over day 1 (intake shown for one day only). Twofactor repeated-measures ANOVA revealed a main effect of day $\left(F_{(3,27)}=42.3 ; p<0.001\right)$, sucrose $\left(F_{(1,9)}=927.2 ; p<0.001\right)$, and sucrose $\times$ day $\left(F_{(3,27)}=44.8 ; p<0.001 ; n=\right.$ $10 /$ group). $C$, Increased weight gain compared with control (water only) animals with sucrose exposure. Two-factor repeated-measures ANOVA shows a significant main effect of day $\left(F_{(5,70)}\right.$ $=600 ; p<0.001)$ whereby both groups gain weight over time, and a significant interaction of sucrose and day $\left(F_{(5,70)}=17.1 ; p<0.001 ; n=10\right.$ /group), suggesting that the sucrose group gains more weight over time.

$\Delta$ FosB (Perrotti et al., 2004, 2005). For further details, see supplemental Methods (available at www.jneurosci.org as supplemental material).

Viral-mediated gene transfer. Surgery was performed on male Sprague Dawley rats. Adeno-associated virus (AAV) vectors were injected bilaterally, $1.5 \mu \mathrm{l}$ per side, into the NAc as described previously (Barrot et al., 2005). Correct placement was verified after experiments on $40 \mu \mathrm{m}$ cresyl-violetstained sections. Vectors included a control expressing only green fluorescent protein (GFP) (AAV-GFP) or an AAV expressing wild-type $\Delta$ FosB and GFP (AAV- $\Delta$ FosB) (Zachariou et al., 2006). Based on the time course of transgene expression within the NAc, animals were tested for behavior 3-4 weeks after injection of AAV vectors, when transgene expression is maximal (Zachariou et al., 2006). For further details, see supplemental Methods (available at www.jneurosci.org as supplemental material).

Statistical analysis. Significance was measured using two-factor repeated-measures ANOVAs as well as Student's $t$ tests, which were corrected where noted for multiple comparisons. Data are expressed as means \pm SEM. Statistical significance was defined as $p<0.05$. 
a

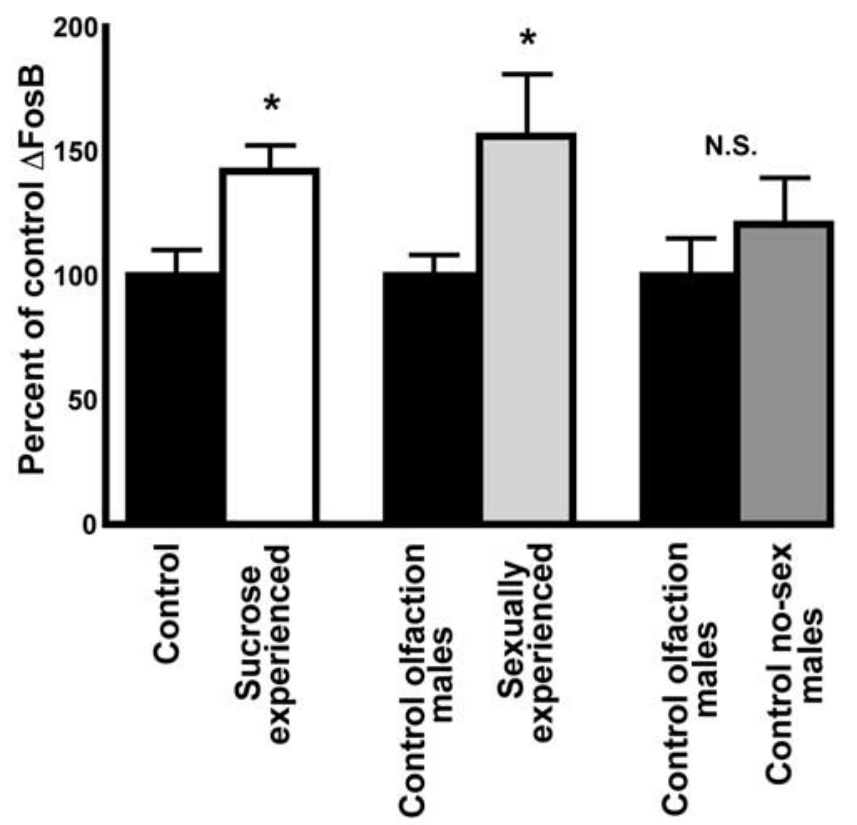

b

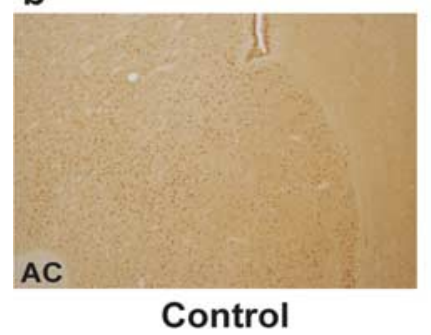

C

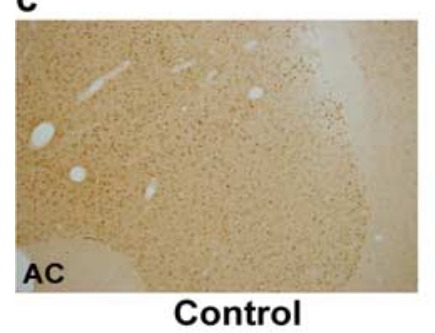

Control
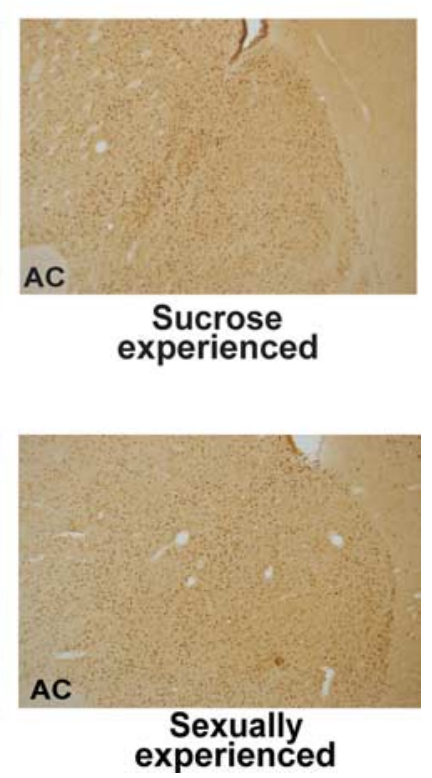

Figure 2. Sucrose consumption and sexual behavior increase $\Delta$ FosB expression in the NAc. $\boldsymbol{a}$, Chronic consumption of $10 \%$ sucrose in a two-bottle choice paradigm, as well as sexual behavior, increase $\Delta$ FosB expression in the NAc by Western blot (sucrose, $t_{(11)}=2.685$; ${ }^{*} p=$ $0.021 ; n=5-8$; sexual behavior, $\left.t_{(12)}=2.351 ;{ }^{*} p=0.037 ; n=6-8\right)$. Olfaction control males do not differ significantly from control no-sex males $\left(t_{(10)}=0.69 ; p>0.50 ; n=4-8\right)$. N.S., Nonsignificant. $\boldsymbol{b}$, Brains sections from sucrose-experienced animals show increased $\Delta$ FosB immunoreactivity compared with control animals in the NAc by immunohistochemistry. Pictures $(10 \times)$ are representative of multiple brain sections from six rats in each treatment group. AC, Anterior commissure. c, Brain sections from sexually experienced animals show increased $\Delta$ FosB immunoreactivity compared with control counterparts in the NAc by immunohistochemistry. Pictures $(10 \times)$ are representative of multiple brain sections from six to eight rats in each treatment group.

\section{Results}

Chronic exposure to sucrose induces increased sucrose intake and sensitization-like behavior

We implemented a two-bottle choice paradigm in which the concentration of sucrose was approximately doubled every $2 \mathrm{~d}$ after
$2 \mathrm{~d}$ of two bottles of water. The sucrose concentration started at $0.125 \%$ and increased to $50 \%$. Animals did not show a sucrose preference until $0.25 \%$ sucrose, and then drank more sucrose than water at all higher concentrations. Starting at the $0.25 \%$ concentration, animals drank increasing volumes of sucrose until a maximum sucrose volume was reached at 5 and $10 \%$. At $20 \%$ and higher, they began to decrease their sucrose volume to maintain steady levels of total sucrose consumption (Fig. $1 a$, inset). After this paradigm, animals spent $6 \mathrm{~d}$ with two bottles of water only, and were then presented with a choice of a $0.125 \%$ sucrose bottle or water for $2 \mathrm{~d}$. Animals drank more sucrose than water at this concentration, and exhibited a significant sucrose preference compared with the lack of preference observed after initial exposure to this sucrose concentration on day 1 .

Because maximum volume intake was reached at a $10 \%$ concentration, naive animals were given a choice between one bottle of water and one bottle of $10 \%$ sucrose for $10 \mathrm{~d}$ and compared with a control group given two bottles of water only. Sucrose animals built to higher levels of sucrose intake by day 10 (Fig. 1b). They also gained significantly more weight after continued sucrose exposure compared with control animals, with the difference in weight increasing over time (Fig. 1c).

\section{Sucrose drinking increases $\Delta$ FosB levels in the NAc}

We analyzed these animals on the $10 \%$ sucrose paradigm for levels of $\Delta$ FosB in the NAc by use of Western blotting (Fig. 2a) and immunohistochemistry (Fig. 2b). Both methods revealed induction of $\Delta$ FosB protein in this brain region in sucrose experienced compared with control animals. Because the entire $\Delta$ FosB protein sequence is contained within that of full-length FosB, antibodies used to detect FosB-like immunoreactivity recognize both proteins (Perrotti et al., 2004, 2005). However, Western blotting revealed that only $\Delta$ FosB was significantly induced by sucrose drinking. This indicates that the difference in signal observed by immunohistochemistry represents $\Delta$ FosB. The increase observed in Figure $2 b$ was found in the NAc core and shell, but not dorsal striatum (data not shown).

\section{Sexual behavior increases $\Delta$ FosB levels in the NAc}

We next investigated the effects of chronic sexual behavior on induction of $\Delta$ FosB in the NAc. Sexually experienced male rats were allowed unlimited access with a receptive female until ejaculation for 14 sessions over an 8-10 week time period. Importantly, control animals were not home-cage controls, but instead were generated by similar handling on testing days and exposure to the open field arena and bedding in which copulation occurred for the same amount of time but without exposure to a receptive female, controlling for olfaction and handling effects. Using Western blotting, we found that sexual experience significantly increased levels of $\Delta$ FosB compared with the control group (Fig. $2 a$ ), with no detectable levels of full-length FosB observed. Consistent with these data, immunohistochemistry revealed an increase in $\Delta$ FosB staining in both core and shell of the NAc (Fig. $2 c$ ), but not dorsal striatum (data not shown).

To ensure that the increase in $\Delta$ FosB observed in the sexually experienced animals was not attributable to social interaction or some other non-mating-related stimulus, we generated nonmating males, which were exposed to hormone-treated females, but not allowed to copulate. These males showed no difference in $\Delta$ FosB levels compared with a separate set of olfaction-arena control animals (Fig. $2 a$ ), suggesting that $\Delta$ FosB induction occurs in response to sexual behavior and not social or nonmating cues. 
Overexpression of $\Delta$ FosB in the NAc increases sucrose intake Using a viral-mediated overexpression system, which enables the stable expression of $\Delta$ FosB over several weeks (Zachariou et al., 2006) (Fig. 3a), we investigated the influence of higher levels of $\Delta$ FosB, specifically targeting the NAc, on sucrose drinking behavior (Fig. $3 b$ ). We first insured that there were no differences in baseline sucrose behavior before surgery with a sucrose intake pretest (AAV-GFP, $6.49 \pm 0.879 \mathrm{ml}$; AAV- $\Delta$ FosB, $6.22 \pm 0.621$ $\mathrm{ml} ; n=15$ /group; $p>0.80$ ). Three weeks after surgery, when $\Delta$ FosB expression had been stable for $\sim 10 \mathrm{~d}$, animals were given a postsurgery sucrose test. The AAV- $\Delta$ FosB group drank significantly more sucrose than the AAV-GFP control group (Fig. 3b). There was no difference in the amount of water intake between the two groups (AAV-GFP, $0.92 \pm 0.019 \mathrm{ml}$; AAV $-\Delta$ FosB, $0.95 \pm$ $0.007 \mathrm{ml} ; n=15 /$ group; $p>0.15$ ), suggesting that the effect of $\Delta$ FosB is specific to sucrose.

\section{Overexpression of $\Delta$ FosB in the NAc influences sexual behavior}

Next, we examined whether $\Delta$ FosB overexpression in the NAc regulates sexual behavior of naive and experienced animals. Although we did not find any differences in parameters of sexual behavior between AAV- $\Delta$ FosB- and -GFP-treated experienced animals (see supplemental Table S1, available at www. jneurosci.org as supplemental material), overexpression of $\Delta$ FosB in naive animals significantly decreased the number of intromissions required to reach ejaculation for the first sexual behavior experience (Fig. 3c). There was also a trend for a decrease in the postejaculatory interval for the $\Delta$ FosB group after the first sexual experience (Fig. $3 c$ ). In contrast, no differences were observed in latencies for mounts, intromissions, or ejaculation in either the naive or experienced animals (see supplemental Table S1, available at www.jneurosci.org as supplemental material). Similarly, no difference was observed for the intromission ratio [number of intromissions/(number of intromissions + number of mounts)], although this may be because of the high variability in the number of mounts in each group.

\section{Sexual experience increases sucrose intake}

Because we found an increase in $\Delta$ FosB levels in the NAc after both sucrose drinking and sexual experience, and $\Delta$ FosB overexpression influences behavioral responses to both rewards, it was of interest to explore whether previous exposure to one of the rewards significantly affected behavioral responses to the other. Before sexual experience, naive animals were randomly assigned to control or sex conditions. Animals were then exposed to sexual experiences or control conditions, as described previously, over $8-10$ weeks. Five days after the last sex session, animals were subjected to a 30 min two-bottle choice paradigm between one bottle of water and one of sucrose. We found that the sexually experienced animals drank significantly more sucrose than controls (Fig. 3b). No difference between sexually experienced and control animals was observed with water intake (control, $1.21 \pm$ $0.142 \mathrm{ml}$; sex experienced, $1.16 \pm 0.159 \mathrm{ml} ; n=7-9 ; p=0.79$ ), suggesting that the effect is specific to sucrose.

\section{Discussion}

This study bridges a previous gap in the literature in elucidating the role of $\Delta$ FosB in natural reward behaviors related to sex and sucrose. We first set out to determine whether $\Delta$ FosB accumulates in the NAc, a crucial brain reward region, after chronic exposure to natural rewards. An important feature of this work was giving the animals a choice in their behavior, by analogy to

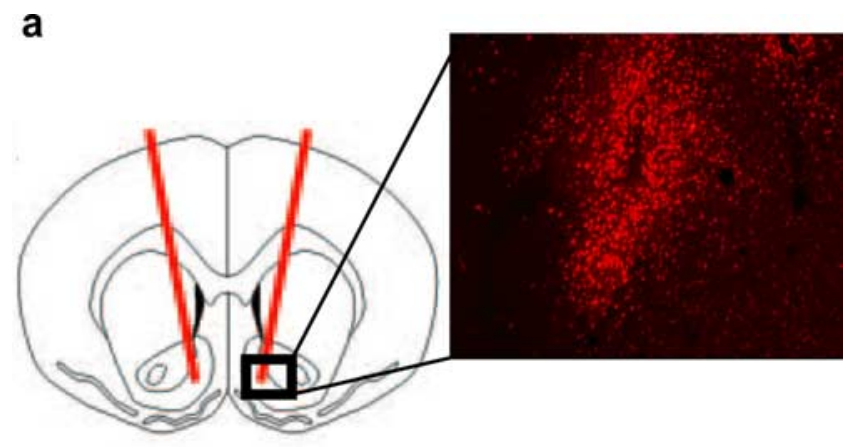

b

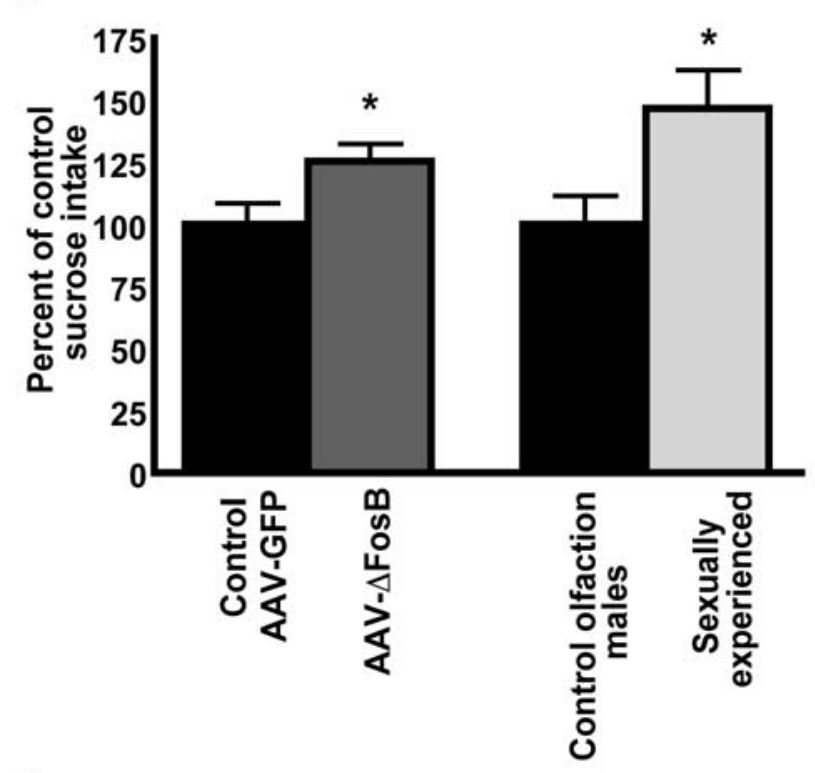

C

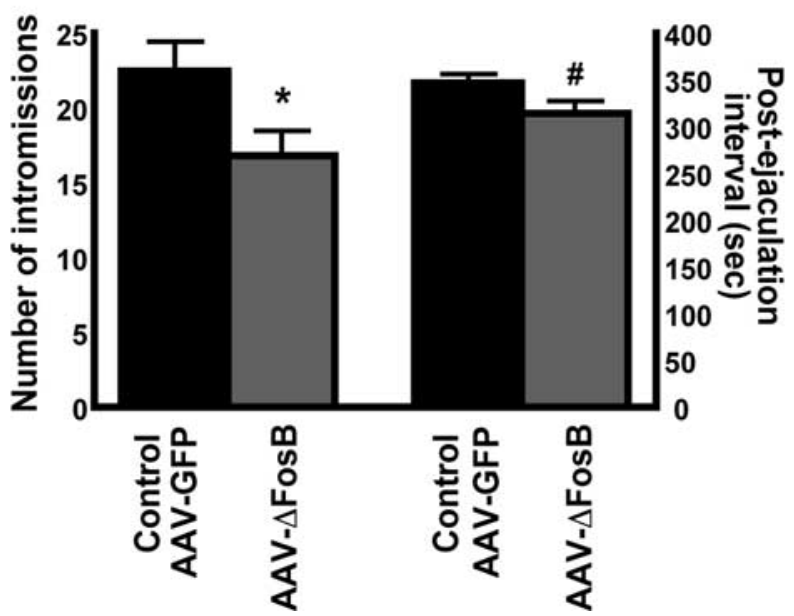

Figure 3. Overexpression of $\triangle F$ osB in the NAc regulates aspects of natural reward behavior. $\boldsymbol{a}$, Depiction of NAc target site by bilateral viral-mediated genetic transfer and example of $\Delta$ FosB expression, detected by immunohistochemistry, after AAV- $\triangle$ FosB injection. $\boldsymbol{b}$, Injection of AAV- $\Delta$ FosB in the NAc results in increased sucrose intake compared with AAV-GFP-injected controls $\left(t_{(28)}=2.208 ;{ }^{*} p=0.036 ; n=15 /\right.$ group $)$. Likewise, 10 weeks of sexual behavior, compared with sexually naive controls, increases sucrose intake $\left(t_{(14)}=2.240\right.$; ${ }^{*} p=0.042$; $n=7-9$ ). c, $\Delta$ FosB overexpression decreases the number of intromissions required to reach ejaculation in sexually naive animals compared with GFP controls $\left(t_{(30)}=2.145 ;{ }^{*} p=0.04\right.$; $n=15-17)$ and results in a trend for decreased postejaculation interval $\left(t_{(30)}=1.916\right.$; ${ }^{\#} p=$ $0.065 ; n=15-17)$. 
drug self-administration paradigms. This was to ensure that any effect on $\Delta$ FosB levels was related to voluntary consumption of the reward. The sucrose model (Fig. 1) demonstrates aspects of addiction-like behavior compared with other sucrose intake models: a choice between reward and control, an inverted U-shaped dose-response curve, a sensitized response after withdrawal, and excessive intake. This model also causes increased weight gain, not seen in other models such as the daily intermittent sugar model (Avena et al., 2008).

Our data establish, for the first time, that two key types of natural rewards, sucrose and sex, both increase $\Delta$ FosB levels in the NAc. These increases were observed by Western blotting and immunohistochemistry; using both methods insures that the observed protein product is indeed $\Delta$ FosB and not full-length FosB, another product of the $f o s B$ gene. The selective induction of $\Delta$ FosB by sucrose and sex is similar to the selective induction of $\Delta$ FosB in the NAc after chronic administration of virtually all types of drugs of abuse (see Introduction). Of note, however, is the observation that the degree of $\Delta$ FosB induction in the NAc observed here in response to natural rewards is smaller than that seen for drug rewards: sucrose drinking and sexual behavior produced a $40-60 \%$ increase in $\Delta$ FosB levels in contrast to the severalfold induction seen with many drugs of abuse (Perrotti et al., 2008).

The second objective of this study was to investigate the functional consequence of $\Delta$ FosB induction in the NAc on natural reward-related behaviors. Much of our previous work on the influence $\Delta$ FosB on drug reward has made use of inducible bitransgenic mice, in which $\Delta$ FosB expression is targeted to the NAc and dorsal striatum. These $\Delta$ FosB-overexpressing mice show enhanced behavioral responses to cocaine and opiates, as well as increased wheel running and instrumental responding for food (see Introduction). In this study, we used a more recently developed viral-mediated gene transfer system to stably overexpress $\Delta$ FosB in targeted brain regions of male rats (Zachariou et al., 2006). We found here that $\Delta$ FosB overexpression increased sucrose intake when compared with control animals, with no differences in water intake between the two groups.

We also investigated how $\Delta$ FosB influences sexual behavior. We demonstrated that $\Delta$ FosB overexpression in the NAc decreases the number of intromissions required for ejaculation in sexually naive animals. This did not correspond with other differences in naive sexual behavior, including alterations in mount, intromission, or ejaculation latencies. In addition, $\Delta$ FosB overexpression did not affect any aspect of sexual behavior in sexually experienced animals. The ability of a manipulation in the NAc to influence sexual behavior is not surprising given the growing evidence that this brain reward region regulates sexual behavior (Balfour et al., 2004; Hull and Dominguez, 2007). The $\Delta$ FosBinduced decrease in number of intromissions could reflect an enhancement of sexual behavior, in that naive animals with $\Delta$ FosB overexpression in the NAc behave more like experienced animals. For example, in tests of repeated sexual experience, animals require fewer intromissions to reach ejaculation (Lumley and Hull, 1999). In addition, the trend for a decrease in the postejaculatory interval with $\Delta$ FosB overexpression also reflects behaviors observed in more sexually motivated, experienced males (Kippin and van der Kooy, 2003). Together, these findings suggest that $\Delta$ FosB overexpression in naive animals may facilitate sexual behavior by making naive animals resemble more experienced or sexually motivated animals. On the other hand, we did not observe a significant effect of $\Delta$ FosB overexpression on experienced sexual behavior. More complex behavioral studies of sex- ual behavior (e.g., conditioned place preference) may better discriminate possible effects of $\Delta$ FosB.

Last, we investigated how previous exposure to one natural reward affects behavioral responses to another. Specifically, we determined the effect of previous sexual experience on sucrose intake. Although both control and sexually experienced animals showed a strong preference for sucrose, the sexually experienced animals drank much more sucrose, with no change in water consumption. This is an interesting finding, in that it suggests that previous exposure to one reward may heighten the rewarding value of another rewarding stimulus, as would be expected if there was a partly shared molecular basis (e.g., $\Delta$ FosB) of reward sensitivity. Similar to this study, female hamsters previously exposed to sexual behavior exhibited enhanced sensitivity to the behavioral effects of cocaine (Bradley and Meisel, 2001). These findings support the notion of plasticity within the brain's reward circuitry, in that the perceived value of present rewards is built on past reward exposures.

In summary, the work presented here provides evidence that, in addition to drugs of abuse, natural rewards induce $\Delta$ FosB levels in the NAc. Likewise, overexpression of $\Delta$ FosB in this brain region regulates an animal's behavioral responses to natural rewards, as has been observed previously for drug rewards. These findings suggest that $\Delta$ FosB plays a more general role in the regulation of reward mechanisms, and may help mediate the crosssensitization observed across many types of drug and natural rewards. As well, our results raise the possibility that $\Delta$ FosB induction in the NAc may mediate not only key aspects of drug addiction, but also aspects of so-called natural addictions involving compulsive consumption of natural rewards.

\section{References}

Avena NM, Rada P, Hoebel BG (2008) Evidence for sugar addiction: behavioral and neurochemical effects of intermittent, excessive sugar intake. Neurosci Biobehav Rev 32:20-39.

Balfour ME, Yu L, Coolen LM (2004) Sexual behavior and sex-associated environmental cues activate the mesolimbic system in male rats. Neuropsychopharmacology 29:718-730.

Barrot M, Olivier JD, Perrotti LI, DiLeone RJ, Berton O, Eisch AJ, Impey S, Storm DR, Neve RL, Yin JC, Zachariou V, Nestler EJ (2002) CREB activity in the nucleus accumbens shell controls gating of behavioral responses to emotional stimuli. Proc Natl Acad Sci U S A 99:11435-11440.

Barrot M, Wallace DL, Bolaños CA, Graham DL, Perrotti LI, Neve RL, Chambliss H, Yin JC, Nestler EJ (2005) Regulation of anxiety and initiation of sexual behavior by CREB in the nucleus accumbens. Proc Natl Acad Sci U S A 102:8357-8362.

Bradley KC, Meisel RL (2001) Sexual behavior induction of c-Fos in the nucleus accumbens and amphetamine-stimulated locomotor activity are sensitized by previous sexual experience in female Syrian hamsters. J Neurosci 21:2123-2130.

Brown JR, Ye H, Bronson RT, Dikkes P, Greenberg ME (1996) A defect in nurturing in mice lacking the immediate early gene fosB. Cell 86:297-309.

Cenci MA (2002) Transcription factors involved in the pathogenesis of L-DOPA-induced dyskinesia in a rat model of Parkinson's disease. Amino Acids 23:105-109.

Colby CR, Whisler K, Steffen C, Nestler EJ, Self DW (2003) Striatal cell type-specific overexpression of DeltaFosB enhances incentive for cocaine. J Neurosci 23:2488-2493.

Hull EM, Dominguez JM (2007) Sexual behavior in male rodents. Horm Behav 52:45-55.

Kelz MB, Chen J, Carlezon WA Jr, Whisler K, Gilden L, Beckmann AM, Steffen C, Zhang YJ, Marotti L, Self DW, Tkatch T, Baranauskas G, Surmeier DJ, Neve RL, Duman RS, Picciotto MR, Nestler EJ (1999) Expression of the transcription factor deltaFosB in the brain controls sensitivity to cocaine. Nature 401:272-276.

Kippin TE, van der Kooy D (2003) Excitotoxic lesions of the tegmental pedunculopontine nucleus impair copulation in naive male rats and block 
the rewarding effects of copulation in experienced male rats. Eur J Neurosci 18:2581-2591.

Lumley LA, Hull EM (1999) Effects of a D1 antagonist and of sexual experience on copulation-induced Fos-like immunoreactivity in the medial preoptic nucleus. Brain Res 829:55-68.

McDaid J, Graham MP, Napier TC (2006) Methamphetamine-induced sensitization differentially alters pCREB and DeltaFosB throughout the limbic circuit of the mammalian brain. Mol Pharmacol 70:2064-2074.

Muller DL, Unterwald EM (2005) D1 dopamine receptors modulate deltaFosB induction in rat striatum after intermittent morphine administration. J Pharmacol Exp Ther 314:148-154.

Nakabeppu Y, Nathans D (1991) A naturally occurring truncated form of FosB that inhibits Fos/Jun transcriptional activity. Cell 64:751-759.

Nestler EJ (2008) Transcriptional mechanisms of addiction: role of $\Delta$ FosB. Philos Trans R Soc Lond B Biol Sci 363:3245-3255.

Olausson P, Jentsch JD, Tronson N, Neve RL, Nestler EJ, Taylor JR (2006) DeltaFosB in the nucleus accumbens regulates food-reinforced instrumental behavior and motivation. J Neurosci 26:9196-9204.

Perrotti LI, Hadeishi Y, Ulery PG, Barrot M, Monteggia L, Duman RS, Nestler
EJ (2004) Induction of deltaFosB in reward-related brain structures after chronic stress. J Neurosci 24:10594-10602.

Perrotti LI, Bolaños CA, Choi KH, Russo SJ, Edwards S, Ulery PG, Wallace DL, Self DW, Nestler EJ, Barrot M (2005) DeltaFosB accumulates in a GABAergic cell population in the posterior tail of the ventral tegmental area after psychostimulant treatment. Eur J Neurosci 21:2817-2824.

Perrotti LI, Weaver RR, Robison B, Renthal W, Maze I, Yazdani S, Elmore RG, Knapp DJ, Selley DE, Martin BR, Sim-Selley L, Bachtell RK, Self DW, Nestler EJ (2008) Distinct patterns of DeltaFosB induction in brain by drugs of abuse. Synapse 62:358-369.

Teegarden SL, Bale TL (2007) Effects of stress on dietary preference and intake are dependent on access and stress sensitivity. Biol Psychiatry 61:1021-1029.

Werme M, Messer C, Olson L, Gilden L, Thorén P, Nestler EJ, Brené S (2002) DeltaFosB regulates wheel running. J Neurosci 22:8133-8138.

Zachariou V, Bolanos CA, Selley DE, Theobald D, Cassidy MP, Kelz MB, Shaw-Lutchman T, Berton O, Sim-Selley LJ, Dileone RJ, Kumar A, Nestler EJ (2006) An essential role for DeltaFosB in the nucleus accumbens in morphine action. Nat Neurosci 9:205-211. 